\title{
Review
}

Acta Haematol 2019;141:151-155

DOI: $10.1159 / 000495454$
Received: March 19, 2018

Accepted after revision: November 14, 2018

Published online: February 15, 2019

\section{Inhibitors: A Need for Eradication?}

\author{
Elena Santagostino ${ }^{a}$ Guy Young ${ }^{b}$ Carmen Escuriola Ettingshausen ${ }^{c}$ \\ Victor Jimenez-Yuste ${ }^{d}$ Manuel Carcao $^{e}$
}

aFondazione IRCCS Ca' Granda Ospedale Maggiore Policlinico, Angelo Bianchi Bonomi Hemophilia and

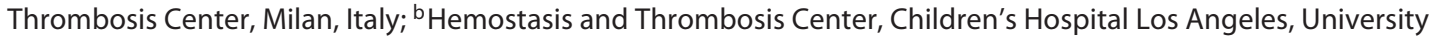
of Southern California Keck School of Medicine, Los Angeles, CA, USA; ${ }^{C} H Z R M$ - Haemophilia Centre Rhein-Main, Mörfelden-Walldorf, Germany; ${ }^{\mathrm{d}}$ Hematology Department, Hospital Universitario La Paz, Autónoma University, IdiPaz, Madrid, Spain; ${ }^{e}$ Division of Hematology/Oncology, Department of Pediatrics and Child Health Evaluative Sciences, Research Institute, Hospital for Sick Children, Toronto, ON, Canada

\section{Keywords}

Hemophilia $\cdot$ Immune tolerance induction · Inhibitors .

Factor VIII concentrate $\cdot$ Von Willebrand factor

\begin{abstract}
The development of inhibitors against factor VIII (FVIII) concentrates represents a significant treatment complication for hemophilia. Immune tolerance induction (ITI) therapy eradicates inhibitors in $60-80 \%$ of patients, resulting in a normal FVIII response. This article, based on presentations at the 6th International Coagulation Meeting, held in Barcelona, Spain, in September 2017, provides an overview of management approaches for patients with inhibitors and briefly tabulates four cases of ITI therapy (first-line or rescue ITI therapy in pediatric and adult patients) with successful outcomes. Switching FVIII product from recombinant FVIII to plasma-derived FVIII/VWF concentrate may be helpful in eradicating inhibitors. The rate of decline of inhibitor titer in the initial stages of ITI therapy is a good indicator of the success or failure of therapy, although prognostic biomarkers are needed. The development of the bispecific monoclonal antibody emicizumab, which was recently shown to reduce bleeding in inhibitor patients, offers a potential alternative
\end{abstract}

\section{KARGER}

() 2019 S. Karger AG, Basel

E-Mail karger@karger.com

www.karger.com/aha therapeutic option. However, the benefits of inhibitor eradication, including a wider choice of cheaper therapeutic products for preventing and treating bleeds, suggest that at least one attempt of ITI therapy should be offered to patients who develop inhibitors.

(c) 2019 S. Karger AG, Basel

The development of factor VIII (FVIII) inhibitors represents a significant treatment complication for individuals with hemophilia. Inhibitors are associated with significant morbidity, including a higher rate of bleeding complications, increased disability due to the development of arthropathies, and a reduced quality of life [1-3].

The concept of immune tolerance induction (ITI) in hemophilia was first reported by Brackmann and Gormsen in 1977 [4]. Over time, a strong consensus has developed in the hemophilia community that ITI should be considered for all patients with FVIII inhibitors, as it leads to a return to a normal FVIII response in $60-80 \%$ of patients in which it is attempted $[3,5]$. ITI therapy is preferable to treatment of inhibitors with FVIII inhibitor bypassing agents (BPA; such as recombinant activated factor VII [rFVIIa] or activated prothrombin complex concentrate [aPCC]), which have less predictable clinical 
hemostatic efficacy (for bleed management, surgery, and prophylaxis) and are a more expensive option in the long term $[6,7]$.

A systematic review of ITI for the treatment of hemophilia A or B concluded that the selection of an ITI regimen should be considered on a case-by-case basis. Moreover, further research is required to establish an optimal protocol for ITI [8]. The best candidates for ITI therapy are children with recently diagnosed inhibitors. In addition, adults with long-standing inhibitors may be suitable for ITI therapy, with selection based on clinical needs and bleeding phenotype [5]. The most important predictor of ITI outcome appears to be peak inhibitor titers both preITI and during ITI. In general, higher peak titers predict a lower likelihood of ITI success. A pre-ITI titer of $<10$ Bethesda units (BU)/mL has been thought to be a predictor of success and this has been used to justify not commencing immediately but instead waiting to start ITI until the inhibitor titer has fallen to $<10 \mathrm{BU}$. However, this approach is being increasingly questioned. One obvious benefit of starting ITI immediately is that it avoids the possibility of breakthrough bleeds while waiting to start ITI. A recent study suggests that the success of ITI may be improved by starting therapy immediately [9].

Some FVIII genotypes such as small insertions, deletions, or missense mutations are also associated with an increased likelihood of ITI success. Factors which are associated with failure of ITI therapy are a long ( $>5$ year) interval between inhibitor diagnosis and ITI initiation and interruption of ITI therapy [1]. Ultimately, the importance of risk factors for success or failure of ITI is that they may influence the ITI regimen selected. In general, patients with a poor prognosis for ITI success should receive more intensive ITI regimens, while patients with a good prognosis for ITI success may perhaps be placed on less intensive ITI regimens [10-13]. ITI regimens that have emerged over time can be divided into: low-dose regimens (generally $25-50 \mathrm{U} / \mathrm{kg} / 3$ times weekly), intermediate-dose regimens (in general around $100 \mathrm{U} / \mathrm{kg} /$ day usually given daily), and high-dose regimens (in general $200-300 \mathrm{U} / \mathrm{kg} /$ day given in 1 or 2 divided doses). Lastly, for very high-risk patients, immunosuppressive therapy can be added to the ITI regimen. Very low-dose ITI therapy (e.g., 10-25 U/kg 3 times weekly) has been reported to be effective for successful immune tolerance in some patients $[14,15]$. This dose range is lower than the low dose (50 U/kg 3 times weekly) recommended by the International Immune Tolerance Study [16]. However, one facet of ITI therapy is the prevention of bleeding in patients, and this is more likely to be achieved with higher doses. Consequently, while good-prognosis patients may be treated with low-dose regimens, poor-prognosis patients should probably be treated with high- or intermediate-dose regimens.

During ITI therapy, it may be necessary to adjust the dose of product or switch the product to achieve success. The rate of decline of inhibitor titers in the early stages of ITI therapy is a good indicator of the likely success or failure of therapy. A rapid decline in inhibitor titer on ITI is predictive of immune tolerance success whereas, in contrast, a slower, or absence of, decline in inhibitor titer is indicative of a higher likelihood of ITI treatment failure. In these patients, the ITI regimen (dose, frequency, or factor) is often changed.

Following successful ITI therapy in which product switching was performed, it may be possible to revert to the original product for prophylactic treatment, if complete and sustained tolerance has been achieved. However, patient preference should be considered, assuming that bleeding is controlled.

For patients on ITI who do not achieve success with first-line ITI therapy, consensus recommendations give the following choices $[17,18]$ : continue with the initial ITI regimen; maximize the ITI dose; switch to von Willebrand factor (VWF)-containing FVIII product if ITI was initiated with a monoclonal or recombinant product; or consider adding rituximab or another immune-modulating drug to the ITI regimen. Indeed, a recent review of ITI therapy by the European Haemophilia Therapy Strategy Board made several recommendations for what to do in the setting of ITI therapy failure: a change of initial ITI regimen was recommended if there was no significant reduction $(\geq 25 \%)$ in inhibitor level within 6-12 months of starting ITI; and a VWF-containing FVIII concentrate should be used in patients initially exposed to highly purified FVIII concentrates [19]. Furthermore, it was recommended that ITI therapy should be discontinued when no further significant decline in inhibitor titer has occurred for an additional 6 months, despite modification of the procedure with the type of product, and a change in dosage - with or without immunosuppression. A decision on a second attempt of ITI therapy should be based on the bleeding phenotype [19].

Studies show conflicting findings regarding whether frequency of bleeding, while on ITI, is a predictor for ITI success. In the International Immune Tolerance study [16], patients randomized to the low-dose ITI regimen experienced more bleeding than patients randomized to the high-dose ITI regimen. However, both groups ultimately achieved similar ITI success rates, suggesting that 
Table 1. Cases of patients who experienced successful ITI with pdFVIII/VWF despite having risk factors for poor ITI success

\begin{tabular}{|c|c|c|c|c|c|}
\hline Case No. & Country & Patient & Risk factors & ITI regimen & Outcome \\
\hline \multicolumn{6}{|c|}{ Primary ITI } \\
\hline 1 & Germany & $\begin{array}{l}\text { Child aged } 9 \text { months } \\
\text { at hemophilia A } \\
\text { diagnosis }\end{array}$ & $\begin{array}{l}22 \text { inversion mutation } \\
\text { No family history } \\
\text { Aged } 11 \text { months at inhibitor onset } \\
\text { Developed inhibitor on pdFVIII/ } \\
\text { VWF concentrate } \\
\text { Peak inhibitor titer }>200 \mathrm{BU} / \mathrm{mL} \\
\text { ITI started } 2.5 \text { weeks after } \\
\text { inhibitor detection }\end{array}$ & $\begin{array}{l}\text { ITI therapy: same pdFVIII/ } \\
\text { VWF } 100 \mathrm{IU} / \mathrm{kg} \text { every } 12 \mathrm{~h} \\
\text { plus aPCC prophylaxis } \\
\text { (Bonn protocol) }\end{array}$ & $\begin{array}{l}\text { Inhibitor levels became undetectable } \\
\text { at } 2.8 \text { months of ITI } \\
\text { Normal FVIII recovery attained at } \\
6.1 \text { months } \\
\text { FVIII pharmacokinetics normalized } \\
\text { at } 9.8 \text { months } \\
\text { HJHS = } 0 \text { (aged } 10 \text { years) }\end{array}$ \\
\hline 2 & Spain & $\begin{array}{l}\text { Adult aged } 49 \text { years } \\
\text { with an inhibitor titer } \\
>10 \mathrm{BU} / \mathrm{mL} \text { at start of } \\
\text { ITI }\end{array}$ & $\begin{array}{l}\text { Developed long-term inhibitor } \\
\text { with on-demand rFVIII } 150 \mu \mathrm{g} / \mathrm{kg} \text {, } \\
\times 3-4 \text { doses plus aPCC } 50 \mathrm{U} / \mathrm{kg} \\
\text { every } 12 \mathrm{~h} \\
\text { No prior ITI therapy; peak } \\
\text { inhibitor titer: } 120 \mathrm{BU} / \mathrm{mL}\end{array}$ & $\begin{array}{l}\text { ITI therapy: pdFVIII/VWF } \\
100 \mathrm{IU} / \mathrm{kg} / \text { day }\end{array}$ & $\begin{array}{l}\text { Patient achieved tolerance in } 10 \\
\text { months and underwent total knee } \\
\text { replacement } \\
\text { Peri- and postoperative hemostasis } \\
\text { maintained successfully with } \\
\text { pdFVIII/VWF treatment }\end{array}$ \\
\hline \multicolumn{6}{|c|}{ Rescue ITI } \\
\hline 3 & Germany & $\begin{array}{l}\text { Child with known } \\
\text { family history of } \\
\text { hemophilia, } \\
\text { developed } \\
\text { cephalohematoma at } \\
\text { birth, } \\
\text { received rFVIII }\end{array}$ & $\begin{array}{l}22 \text { inversion mutation } \\
\text { Aged } 1.6 \text { years at inhibitor onset } \\
\text { (after } 7 \text { EDs) } \\
\text { ITI started at } 3 \text { years of age } \\
\text { (delayed until inhibitor titer }<10 \\
\text { BU } / \mathrm{mL} \text { ) }\end{array}$ & $\begin{array}{l}\text { Initial ITI: rFVIII } 100 \mathrm{IU} / \\
\text { kg every } 12 \mathrm{~h} \text { (Bonn } \\
\text { protocol) } \\
\text { Switched ITI: to pdFVIII/ } \\
\text { VWF concentrate (100 IU/ } \\
\text { kg twice daily) }\end{array}$ & $\begin{array}{l}\text { Peak inhibitor titer after initial ITI: } \\
65.9 \mathrm{BU} / \mathrm{mL} \\
\text { After } 18 \text { months of initial ITI, } \\
\text { inhibitor level still } 17 \mathrm{BU} / \mathrm{mL} \\
\text { After switching to pdFVIII/VWF } \\
\text { ITI, negative Bethesda achieved after } \\
6 \text { months } \\
\text { Normal FVIII recovery achieved } \\
\text { after } 9.2 \text { months } \\
\text { FVIII half-life normalized after } 14.3 \\
\text { months } \\
\text { Patient continued with pdFVIII/ } \\
\text { VWF every other day (follow-up } \\
\text { period: } 17.1 \text { years) } \\
\text { No inhibitor recurrence; HJHS = } 0\end{array}$ \\
\hline 4 & USA & Child aged 16 months & $\begin{array}{l}\text { Older sibling with FVIII inhibitor; } \\
\text { Inhibitor onset (titer: } 2.6 \mathrm{BU} / \mathrm{mL} \text { ) } \\
\text { at } 18 \text { months of age }\end{array}$ & $\begin{array}{l}\text { Initial prophylaxis: rFVIII } \\
40 \text { IU/kg } 3 \text { times per week } \\
\text { Initial ITI: rFVIII } 60 \mathrm{IU} / \mathrm{kg} \\
\text { every other day for } 3 \\
\text { months, then daily } \\
\text { Switched ITI: to pdFVIII/ } \\
\text { VWF } 100 \mathrm{IU} / \mathrm{kg} / \text { day }\end{array}$ & $\begin{array}{l}\text { Patient failed using a low-dose } \\
\text { protocol with a rFVIII ( } 40 \mathrm{IU} / \mathrm{kg} 3 \\
\text { times per week, then } 60 \mathrm{IU} / \mathrm{kg} \text { ) } \\
\text { After } 1 \text { year of switching to pdFVIII/ } \\
\text { VWF, ITI was successful (negative } \\
\text { titer, FVIII half-life normalized) and } \\
\text { patient switched to prophylactic } \\
\text { pdFVIII/VWF } 50 \mathrm{IU} / \mathrm{kg} 3 \text { times per } \\
\text { week }\end{array}$ \\
\hline
\end{tabular}

aPCC, activated prothrombin complex concentrate; BU, Bethesda units; EDs, exposure days; HJHS, Haemophilia Joint Health Score; ITI, immune tolerance induction; pdFVIII, plasma-derived factor VIII; rFVIII, recombinant factor VIII; VWF, von Willebrand factor.

the higher frequency of bleeding did not reduce the ITI success rate. In contrast, the ongoing Observational Immune Tolerance Induction study (ObsITI) showed an association between increased bleeding frequency and reduced ITI success rate [20]. It might be that bleeding frequency on ITI is related to patients' inhibitor titers; higher inhibitor titers are associated with more bleeding and with a lower rate of ITI success.

The benefit of treating inhibitors with a rescue ITI regimen using VWF-containing plasma-derived FVIII
(pdFVIII/VWF) concentrate was demonstrated in a large, retrospective analysis of data from 22 centers in Spain, Italy, and Germany, as part of the Grifols ITI study [10]. Combined complete and partial success rates with pdFVIII/VWF were 87 and $74 \%$ in primary ITI and rescue ITI, respectively; patients undergoing rescue ITI had a higher risk profile for ITI failure [10].

Table 1 summarizes 4 cases of patients who experienced successful ITI with pdFVIII/VWF despite having risk factors for poor ITI success. 
Our understanding of ITI therapy is incomplete. One of the many unanswered questions is whether co-administration of immunosuppressants would improve efficacy. For patients who fail rescue ITI therapy, rituximab, or alternative immunosuppressants (e.g., corticosteroids, mycophenolate mofetil, rapamycin, or combinations of these) have been used [21, 22]. However, the possible long-term adverse effects of these agents have limited their use. Ultimately what is needed is some early biological predictor (i.e., biomarker) for ITI success/failure $[23,24]$. This might also allow clinicians to tailor the ITI regimen (e.g., change product, add a specific immunosuppressive agent) to the patient and to not carry on with an ITI regimen that is predicted to result in failure. This could result in considerable cost savings.

Given that the bispecific monoclonal antibody emicizumab has demonstrated significant reductions in bleeding in inhibitor patients [25], a question that has now been raised is: should ITI still be offered to patients who develop inhibitors? The current opinion amongst hemophilia treaters is that the majority would still opt for at least one round of ITI therapy. The rationale for this is that successful eradication of an inhibitor may allow more and safer therapeutic options for the patient in the future to prevent bleeds (e.g., gene therapy) and to treat bleeds (with FVIII replacement rather than BPA). Of course, there may be some patients or families who are unable to cope with the demands of ITI therapy and may now opt for emicizumab rather than undertaking ITI.
Furthermore, emicizumab may be prescribed to patients undergoing ITI for the purpose of preventing bleeding until tolerance is achieved. Closely following patients who develop inhibitors and are treated in different manners will be critical for safety surveillance and to develop future therapeutic guidelines.

\section{Acknowledgements}

Professional medical writing assistance was provided by David P. Figgitt, PhD, ISMPP CMPPTM, Content Ed Net, under the direction of the authors, with funding from Grifols, Spain, a manufacturer of plasma-derived FVIII concentrates.

\section{Disclosure Statement}

E.S.: Advisory Board membership for Bayer, Grifols, Novo Nordisk, Octapharma, Baxalta/Shire, Pfizer, Kedrion, Sobi, and Roche, and speaker fees from Grifols, Bioverativ, Sobi, Bayer, CSL Behring, Novo Nordisk, Octapharma, Pfizer, Baxalta/Shire, Kedrion, and Roche. G.Y.: no conflicts of interest to declare. C.E.E.: no conflicts of interest to declare. V.J.Y.: reimbursement for attending symposia/congresses and/or honoraria for speaking and/ or honoraria for consulting, and/or funds for research from Shire, Bayer, CSL-Behring, Grifols, Novo Nordisk, Sobi, Octapharma, and Pfizer. M.C.: research support from Bayer, Bioverativ, Novo Nordisk, Octapharma, Pfizer, and Shire; honoraria/speaker fees from Bayer, Bioverativ, Biotest, CSL Behring, Grifols, Novo Nordisk, Octapharma, Pfizer, and Shire, and advisory board/consultancy work for Bayer, Bioverativ, CSL Behring, Novo Nordisk, Octapharma, Pfizer, and Shire.

\section{References}

1 Witmer C, Young G. Factor VIII inhibitors in hemophilia A: rationale and latest evidence. Ther Adv Hematol. 2013 Feb;4(1):59-72.

2 Santagostino E. More than a decade of international experience with a pdFVIII/VWF concentrate in immune tolerance. Haemophilia. 2013 Jan;19 Suppl 1:8-11.

3 Di Minno G, Coppola A. A role for von Willebrand factor in immune tolerance induction in patients with haemophilia A and inhibitors? Blood Transfus. 2011 May;9 Suppl 2:s14-20.

4 Brackmann HH, Gormsen J. Massive factorVIII infusion in haemophiliac with factorVIII inhibitor, high responder. Lancet. 1977 Oct;2(8044):933.

5 Coppola A, Di Minno MN, Santagostino E. Optimizing management of immune tolerance induction in patients with severe haemophilia A and inhibitors: towards evidencebased approaches. Br J Haematol. 2010 Sep; 150(5):515-28.
6 Earnshaw SR, Graham CN, McDade CL, Spears JB, Kessler CM. Factor VIII alloantibody inhibitors: cost analysis of immune tolerance induction vs. prophylaxis and on-demand with bypass treatment. Haemophilia. 2015 May;21(3):310-9.

7 Gomez K, Klamroth R, Mahlangu J, Mancuso $\mathrm{ME}$, Mingot ME, Ozelo MC. Key issues in inhibitor management in patients with haemophilia. Blood Transfus. 2014 Jan;12 Suppl 1:s319-29.

8 Athale $\mathrm{AH}$, Marcucci M, Iorio A. Immune tolerance induction for treating inhibitors in people with congenital haemophilia A or B. Cochrane Database Syst Rev. 2014 Apr;(4):CD010561.

9 Nakar C, Manco-Johnson MJ, Lail A, Donfield S, Maahs J, Chong Y, et al. Prompt immune tolerance induction at inhibitor diagnosis regardless of titre may increase overall success in haemophilia A complicated by inhibitors: experience of two U.S. centres. Haemophilia. 2015 May;21(3):365-73.
10 Oldenburg J, Jiménez-Yuste V, Peiró-Jordán R, Aledort LM, Santagostino E. Primary and rescue immune tolerance induction in children and adults: a multicentre international study with a VWF-containing plasma-derived FVIII concentrate. Haemophilia. 2014 Jan;20(1):83-91.

11 DiMichele DM, Kroner BL; North American Immune Tolerance Study Group. The North American Immune Tolerance Registry: practices, outcomes, outcome predictors. Thromb Haemost. 2002 Jan;87(1):52-7.

12 Gringeri A, Musso R, Mazzucconi MG, Piseddu G, Schiavoni M, Pignoloni P, et al.; RITSFITNHES Study Group. Immune tolerance induction with a high purity von Willebrand factor/VIII complex concentrate in haemophilia A patients with inhibitors at high risk of a poor response. Haemophilia. $2007 \mathrm{Jul}$; $13(4): 373-9$. 
13 Kurth M, Puetz J, Kouides P, Sanders J, Sexauer $\mathrm{C}$, Bernstein J, et al. The use of a single von Willebrand factor-containing, plasmaderived FVIII product in hemophilia A immune tolerance induction: the US experience. J Thromb Haemost. 2011 Nov;9(11):2229-34.

14 Van Leeuwen EF, Mauser-Bunschoten EP, Van Dijken PJ, Kok AJ, Sjamsoedin-Visser EJ, Sixma JJ. Disappearance of factor VIII:C antibodies in patients with haemophilia A upon frequent administration of factor VIII in intermediate or low dose. Br J Haematol. 1986 Oct; 64(2):291-7.

15 Ter Avest PC, Fischer K, Gouw SC, Van Dijk K, Mauser-Bunschoten EP. Successful low dose immune tolerance induction in severe haemophilia A with inhibitors below 40 Bethesda Units. Haemophilia. 2010 May; 16(102):71-9.

16 Hay CR, DiMichele DM; International Immune Tolerance Study. The principal results of the International Immune Tolerance Study: a randomized dose comparison. Blood. 2012 Feb;119(6):1335-44.
17 DiMichele DM, Hoots WK, Pipe SW, Rivard GE, Santagostino E. International workshop on immune tolerance induction: consensus recommendations. Haemophilia. 2007 Jul; 13(s1 Suppl 1):1-22.

18 Valentino LA, Kempton CL, Kruse-Jarres R, Mathew P, Meeks SL, Reiss UM; International Immune Tolerance Induction Study Investigators. US Guidelines for immune tolerance induction in patients with haemophilia a and inhibitors. Haemophilia. 2015 Sep;21(5):55967.

19 Holstein K, Batorova A, Carvalho M, Fijnvandraat K, Holme P, Kavakli K, et al.; European Haemophilia Therapy Strategy Board (EHTSB). Current view and outcome of ITI therapy - A change over time? Thromb Res. 2016 Dec;148:38-44.

20 Kreuz W, Escuriola Ettingshausen C, Vdovin V, Zozulya N, Plyushch O, Svirin P, et al.; ObsITI study group; ObsITI committee. First prospective report on immune tolerance in poor risk haemophilia A inhibitor patients with a single factor VIII/von Willebrand factor concentrate in an observational immune tolerance induction study. Haemophilia. 2016 Jan;22(1):87-95.
21 Beutel K, Hauch H, Rischewski J, Kordes U, Schneppenheim J, Schneppenheim R. ITI with high-dose FIX and combined immunosuppressive therapy in a patient with severe haemophilia B and inhibitor. Hamostaseologie. 2009 May;29(2):155-7.

22 Mancuso ME, Cannavò A. Immune tolerance induction in hemophilia. Clin Invest (Lond). 2015;5(3):321-35.

23 van Helden PM, van den Berg HM, Gouw SC, Kaijen PH, Zuurveld MG, Mauser-Bunschoten EP, et al. IgG subclasses of anti-FVIII antibodies during immune tolerance induction in patients with hemophilia $\mathrm{A}$. Br J Haematol. 2008 Aug;142(4):644-52.

24 Lapalud P, Rothschild C, Mathieu-Dupas E, Balicchi J, Gruel Y, Laune D, et al. Anti-A2 and anti-A1 domain antibodies are potential predictors of immune tolerance induction outcome in children with hemophilia A. J Thromb Haemost. 2015 Apr;13(4):540-7.

25 Oldenburg J, Mahlangu JN, Kim B, Schmitt C, Callaghan MU, Young G, et al. Emicizumab prophylaxis in hemophilia A with inhibitors. N Engl J Med. 2017 Aug;377(9):809-18. 